\title{
Ratchetting in Cold-Drawn Pearlitic Steel Wires
}

\author{
LUNWEI LIANG, LIANG XIANG, YUNJIANG WANG, YAN CHEN, \\ HAIYING WANG, and LANHONG DAI
}

\begin{abstract}
The microscopic mechanisms that accommodate uniaxial ratchetting in cold-drawn pearlitic steel wires were explored. A two-stage evolution of ratchetting strain as a function of cycle numbers was observed. The initial sudden increase of plastic strain leads to a rapid decomposition of cementite, followed by a constant ratchetting strain rate with critical role of decomposed carbon atoms played in blocking dislocation motion. The dislocation configuration transforms from low-density lines and tangles to high-density cells and sub-grains with increasing strain. A possible mechanism of cementite decomposition is discussed in terms of carbon-dislocation interactions and an unfavorable cementite surface-to-volume ratio.
\end{abstract}

https://doi.org/10.1007/s11661-019-05359-x

(C) The Minerals, Metals \& Materials Society and ASM International 2019

\section{INTRODUCTION}

COLD-DRAWN pearlitic steel wires that consist of alternating lamellae of body-centered cubic (BCC) ferrite and orthorhombic cementite are used widely as engineering structures, such as arrester wires of aircraft carriers, suspension bridge cables, and tire cords owing to their excellent combination of high strength and reasonable ductility. ${ }^{[1]}$ Mechanical properties of colddrawn pearlitic steel wires are controlled mainly by precipitations of cementite in ferrite phase, although the hard cementite phase accounts for only approximately one-ninth of the total volume in pearlite. Hence, the formation and evolution of cementite have been studied extensively over the past decades. ${ }^{[2-35]}$ The deformation and slip planes of cementite in pearlitic steels have been investigated. ${ }^{[2-6]}$ Many studies have reported that cementite undergoes dissolution during cold drawing. ${ }^{[7-17]}$ The partial amorphization of cementite in heavily drawn eutectoid steels was found. ${ }^{[18-20]}$ Some studies indicated that cementite should be considered as an interstitial phase $\mathrm{Fe}_{3} \mathrm{C}_{1-\mathrm{x}},{ }^{[21,22]}$ although cementite is commonly regarded as a stoichiometric compound

LUNWEI LIANG, YUNJIANG WANG, YAN CHEN, HAIYING WANG, and LANHONG DAI are with the State Key Laboratory of Nonlinear Mechanics, Institute of Mechanics, Chinese Academy of Sciences, Beijing, 100190, P.R. China and also with the School of Engineering Science, University of Chinese Academy of Sciences, Beijing, 101408, P.R. China. Contact e-mail: lhdai@1nm.imech.ac.cn LIANG XIANG is with the State Key Laboratory of Nonlinear Mechanics, Institute of Mechanics, Chinese Academy of Sciences and with the School of Engineering Science, University of Chinese Academy of Sciences, and also with the Institute of Systems Engineering, China Academy of Engineering Physics, Mianyang, 621999, Sichuan, P.R. China.

Manuscript submitted December 7, 2018.
$\mathrm{Fe}_{3} \mathrm{C}$. Recently, atom probe field ion microscopy (APFIM), ${ }^{[23-25]}$ three-dimensional atom probe (3DAP) ${ }^{[24,26-29]}$ and Mössbauer spectroscopy ${ }^{[30-34]}$ studies have reported that cementite dissolves during cold-drawn deformation at room temperature. Two main mechanisms of cementite dissolution have been proposed. The first mechanism is attributed to the interaction between dislocations and carbon atoms, since the binding enthalpy between the carbon atoms and the dislocations in ferrite is higher than that between carbon and iron atoms in cementite. ${ }^{[7,35]}$ The second mechanism is ascribed to the destabilization of cementite because of an increase in free energy. ${ }^{[8,10]}$

Ratchetting, ${ }^{[36-38]}$ which is a cyclic accumulation of inelastic deformation that is generated from an asymmetric stress-controlled cyclic loading, can reduce the fatigue life of engineering structures. ${ }^{[39]}$ Some components made from pearlitic steels, such as steel wire ropes in mine hoists and tower cranes, inevitably undergo ratchetting during cyclic starting and braking. It is critical to investigate the ratchetting behavior of pearlitic steels for safety assessments and life estimation. During the past 30 years, most phenomenological theoretical constitutive models ${ }^{[38,40]}$ which were based on the Armstrong-Frederick model ${ }^{[41]}$ have been constructed from macroscopic experimental results without considering microscopic physical information. Recently, multi-mechanism models that were reviewed by Saï et al. ${ }^{[42]}$ which merged the physical nature of the cyclic deformation into the constitutive models, provide a new way to predict ratchetting deformation more accurately. To improve the capacity to predict the ratchetting behavior, more micro-mechanisms should be included in the multi-mechanism models with fewer empirical variables and parameters. 
For the microscopic mechanism of ratchetting, considerable attention has been given to dislocation patterns and their evolution in stainless steels. ${ }^{[39,43-48]}$ Research on the microstructure of ratchetting has focused mainly on face-centered cubic crystal structures. Recently, the dislocation patterns and their evolution of polycrystalline 20 ordinary carbon steels (BCC) have been characterized during uniaxial ratchetting deformation. ${ }^{[49]}$ However, the mechanisms that underlie ratchetting, and that are associated with dislocation evolution and cementite decomposition in cold-drawn pearlitic steel wires have not been involved in multi-mechanism models.

The purpose of this work was to elucidate the effect of cementite decomposition and dislocation evolution on ratchetting in cold-drawn pearlitic steel wires at room temperature. Possible mechanisms of cementite decomposition and its effect on dislocation motion during ratchetting deformation are discussed.

\section{EXPERIMENTAL PROCEDURE}

Cold-drawn pearlitic steel wires were studied, and their chemical composition is shown in Table I. Steel rods were quenched in a salt bath at $\sim 550{ }^{\circ} \mathrm{C}$ after being austenized fully at $900{ }^{\circ} \mathrm{C}$, and having completed isothermal pearlitic transformation. Patented wires of $2.90 \mathrm{~mm}$ diameter were drawn to a diameter of $0.90 \mathrm{~mm}$ with a true strain of $\varepsilon=2 \ln \left(d_{0} / d\right)=2.34$, where $d_{0}$ and $d$ are the initial and final wire diameters, respectively. ${ }^{[50]}$ To avoid distinct rise of temperature during deformation, the wires were wet-drawn in a liquid lubricant vessel. The total area reduction was $\sim 90.4$ pct. Specimens with a gauge length of $120 \mathrm{~mm}$ and a gauge diameter of $0.9 \mathrm{~mm}$ were machined according to the Chinese National Standard GB/T228.1-2010.

Before performing the ratchetting tests, monotonic tension tests were carried out to obtain the tensile properties, which are useful to determine the loading stress level. The specimen was tested under strain-controlled monotonic tension with an applied strain rate of $4 \times 10^{-4} \mathrm{~s}^{-1}$. Figure 1 shows the engineering stressstrain curve, and the tensile properties are shown in Table II. No yielding plateau exists, as shown in Figure 1. The tests were repeated at least three times.

Uniaxial stress-controlled cyclic tests were conducted at the same stress level $(1100 \pm 750 \mathrm{MPa}$, i.e., a mean stress of $1100 \mathrm{MPa}$ and a stress amplitude of $750 \mathrm{MPa}$ ) with a frequency of $1 \mathrm{~Hz}$ at room temperature on an MTS 810-100 kN servo-hydraulic testing machine. At least three samples were measured for each condition to assess the reproducibility of the results. Ratchetting strain is defined as: $\varepsilon_{\mathrm{r}}=\left(\varepsilon_{\max }+\varepsilon_{\min }\right) / 2$, where $\varepsilon_{\max }$ and $\varepsilon_{\text {min }}$ are the maximum and minimum axial normal strain in each cycle, respectively. The ratchetting strain rate is defined as the increment of ratchetting strain $\varepsilon_{\mathrm{r}}$ in each cycle and is denoted $\mathrm{d} \varepsilon_{\mathrm{r}} / \mathrm{d} N$, where $N$ is the number of cycles.

The microstructures were investigated by scanning electron microscopy (SEM) by using TESCAN LYRA3 FEG-SEM/FIB and by transmission electron microscopy (TEM) by using a JEOL JEM-2100F instrument operated at $200 \mathrm{kV}$. The specimens for analysis were cut from the center of the wires in the direction of the longitudinal axis.

Mössbauer analysis was performed at room temperature by using a Wissel constant acceleration Mössbauer spectrum device (Germany) with a ${ }^{57} \mathrm{Co}(\mathrm{Pd})$ source. Three samples were measured for each number of cycles.

\section{RESULTS}

\section{A. Ratchetting Behavior}

Figures 2(a) and (b) show the stress-strain response and ratchetting strain-cycle curve, respectively. It is observed from Figure 2(b) that a two-stage evolution exists. One stage is a decreased ratchetting strain rate with loading cycles in stage I, and the other is a nearly constant ratchetting strain rate in stage II. The initial ratchetting strain in the first cycle reaches approximately 1.44 pct. The ratchetting strain increases from 1.44 to 1.88 pct during cyclic loading deformation. An increase of only 31 pet in ratchetting strain occurs, which is relatively small. Moreover, the cyclic responses are

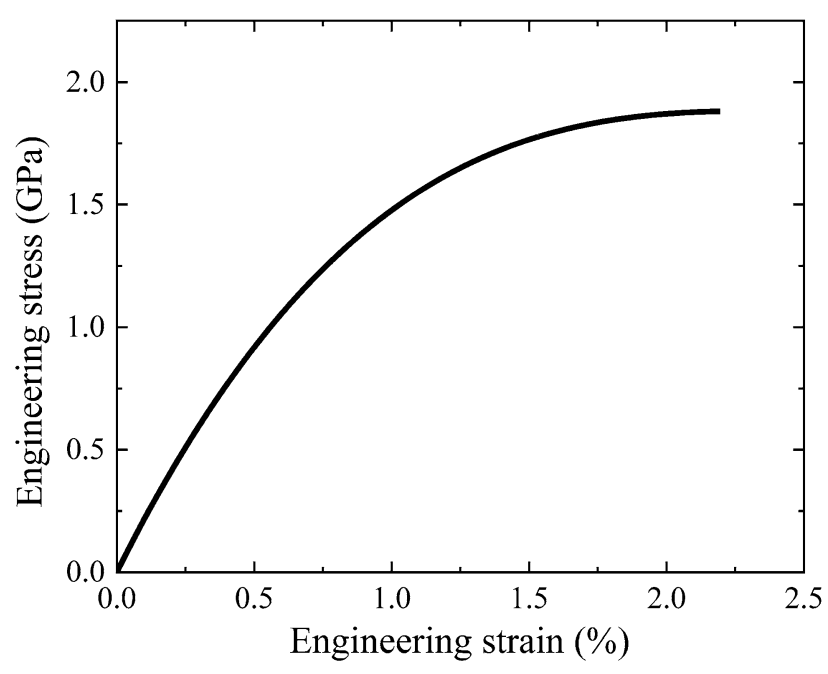

Fig. 1-Typical engineering uniaxial tensile stress-strain curve for investigated steel wire.

Table I. Chemical Composition of Pearlitic Steel Wire (in Weight Percent)

\begin{tabular}{lcccccccr}
\hline $\mathrm{C}$ & $\mathrm{P}$ & $\mathrm{Si}$ & $\mathrm{S}$ & $\mathrm{Cr}$ & $\mathrm{Cu}$ & $\mathrm{Mn}$ & $\mathrm{Ni}$ & $\mathrm{Fe}$ \\
\hline 0.72 & 0.024 & 0.24 & 0.008 & 0.021 & 0.051 & 0.51 & 0.012 & balanced \\
\hline
\end{tabular}


Table II. Tensile Properties of Pearlitic Steel Wire

\begin{tabular}{lccc}
\hline Yield Stress $\left(\sigma_{0.2}, \mathrm{MPa}\right)$ & Ultimate Tensile Stress $(\mathrm{MPa})$ & Total Elongation $(\mathrm{Pct})$ & Young's Modulus $(\mathrm{GPa})$ \\
\hline $1514 \pm 11$ & $1913 \pm 32$ & $2.11 \pm 0.17$ & $186 \pm 2$ \\
\hline
\end{tabular}

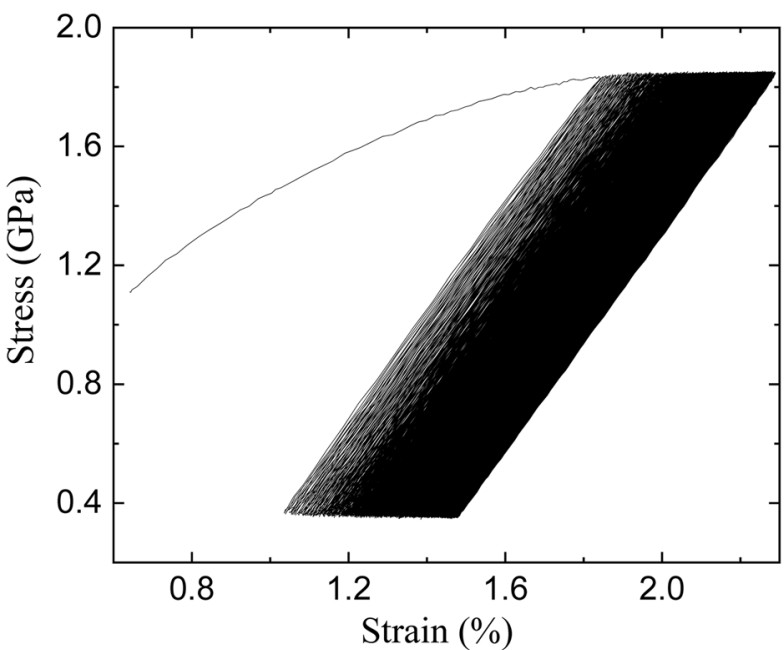

(a)

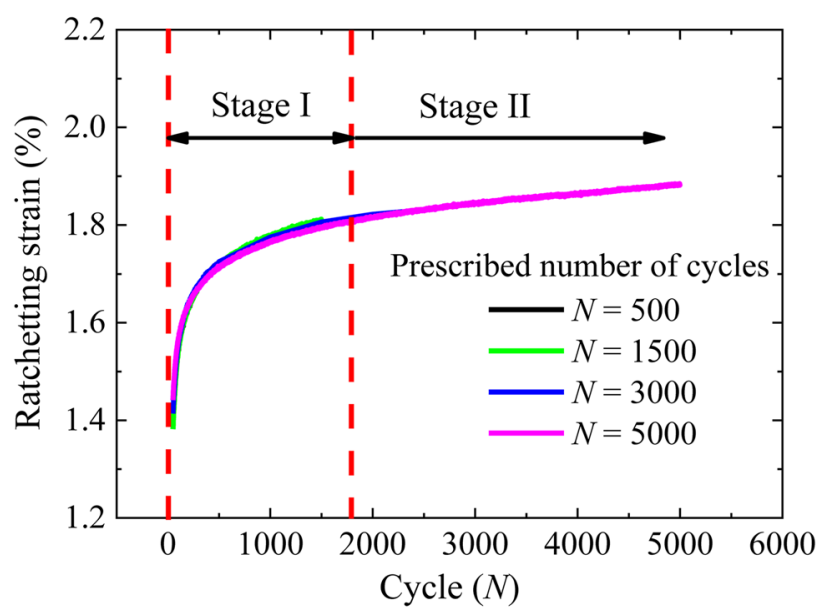

(b)

Fig. 2-(a) Cyclic stress-strain curve, and (b) variation of ratchetting strain as a function of cycles.

almost repeatable for samples with different prescribed numbers of cycles, as shown in Figure 2(b).

\section{B. Pearlite Interlamellar Spacing}

Figures 3(a) and (b) show the microstructures of the initial transverse section and the pearlite interlamellar spacing as a function of cycles, respectively. Figure 3(a) shows the large variation of the initial lamellar orientation in cold-drawn pearlitic steel wires. To characterize the evolution of this lamellar structure, the interlamellar spacing (ILS) is defined as the perpendicular distance across two consecutive lamellae of ferrite and cementite. ${ }^{[51]} \mathrm{A}$ circular line method, ${ }^{[52]}$ which is effective for a randomly distributed lamellar structure, was used to measure the average ILS, which is computed as: $d=0.5 L / n$, where $L$ is the length of the circle and $n$ is the number of intersections between the circular line and the lamellae. The initial average ILS is $\sim 59 \mathrm{~nm}$. Figure 3(b) shows the ILS was reduced by $\sim 12$ pct up to 5000 cycles. However, for geometrical reasons, an elongation of 2.0 pct only resulted in a transverse section contraction ratio of $\sim 1.0 \mathrm{pct}$, which is one order of magnitude lower than the above changes in ILS. The question arises: why does the observed small strain respond to larger changes in ILS? Different from an almost perfect lamellar structure in $\mathrm{Hu}$ et al. ${ }^{[52]}$ the partial initial lamellar structure has been broken in our materials (shown in Figure 3(c)). Figure 3(d) shows the microstructures of the transverse section after 5000 cycles. The twist and extrusion deformation of the broken lamellar structure during cyclic loading deformation may cause topological changes that lead to an increase in the number of intersections $n$ (shown in Figure 3(e)), which results in a rapid decrease in the ILS in subsequent cyclic loading. Additionally, the experimental results of the ILS exhibit a large dispersion (shown in Figure 3(b)).

It is concluded from Figure 3(b) that the ILS shows a remarkable decrease in the initial number of cycles, which suggests an increase in unfavorable surface-to-volume ratio of cementite. Then the ILS remains nearly unchanged during the later cyclic loading.

\section{Dislocation Structures}

Figure 4 shows the dislocation features at different stages of ratchetting deformation for the prescribed number of cycles. It is concluded that dislocation structures transform from dislocation patterns with a low dislocation density, such as dislocation lines and tangles, to those with a high dislocation density, such as dislocation cells and sub-grains. Figure 4(a) shows that the initial dislocation pattern consists of parallel distributed dislocation lines. The dislocation tangles are formed after 500 cycles (shown in Figure 4(b)) where the initially parallel dislocation structure is no longer maintained, which suggests that new dislocations nucleate from the ferrite-cementite interface. With an increase in cyclic numbers, dislocation cells are formed (shown in Figure 4(c)), as was obtained by Li et al. ${ }^{[53]}$ After 5000 cycles, sub-grains form by dislocation rearrangement in the dislocation cells since cross-slip in the BCC crystals is easily achieved (shown in Figure 4(d)), suggesting no apparent increase in dislocation density at stage II.

\section{Cementite Decomposition}

Figure 5 shows the Mössbauer spectrum of the steel at a different number of cycles. Figure 6 shows the fraction of cementite with cyclic numbers. Mössbauer 

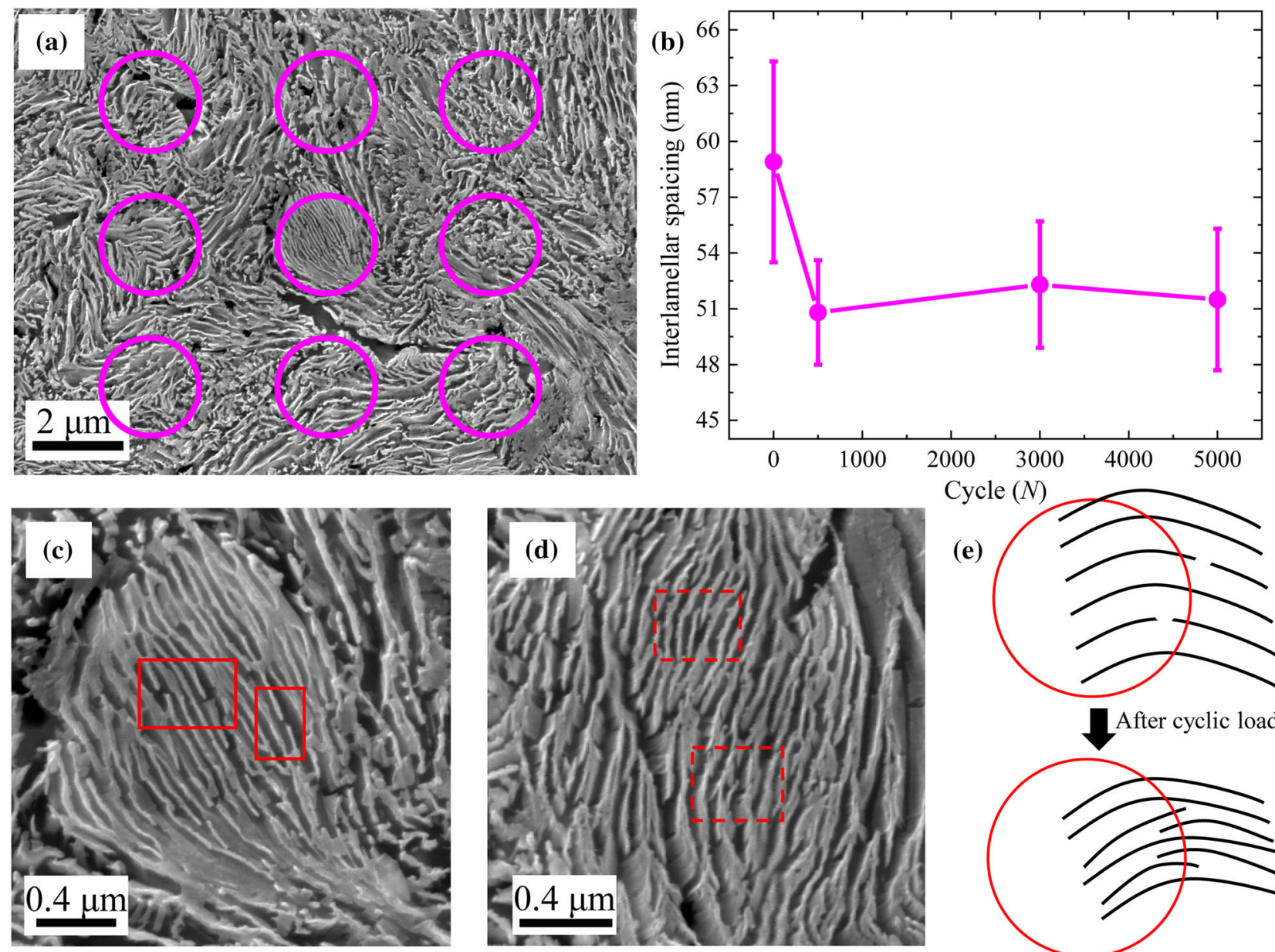

(e)

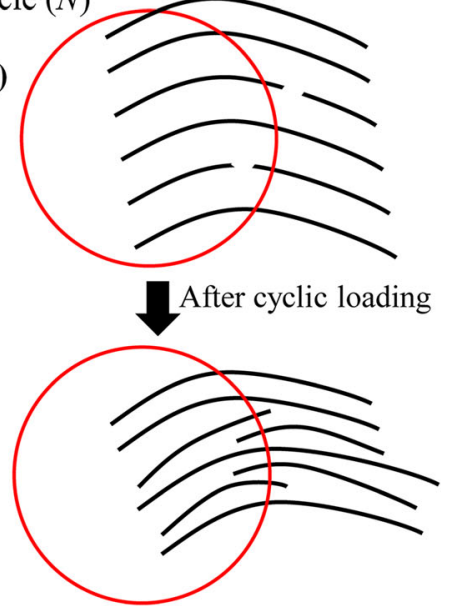

Fig. 3-(a) SEM images of initial transverse section. (b) Pearlite interlamellar spacing as a function of cyclic numbers. (c) Partial broken cementite lamellae of initial transverse section. (d) SEM image of transverse section after 5000 cycles. (e) Schematic diagram illustrating evolution of pearlitic lamellar structure and increase in number of intersections between the circle and the pearlitic lamellae. Pink circles in (a) indicate positions for measuring the interlamellar spacing by using a circular line method. The solid rectangles in (c) denote the broken cementite lamellae. The dotted rectangles in (d) correspond to the twisted cementite lamellae. The black lines and the red circles in (e) represent the pearlitic lamellae and the measuring position, respectively.

spectra of the complicated solid solution trend to derive from the superposition of several six-line patterns, each of which corresponds to different impurity neighborhoods. ${ }^{[33]}$ Therefore, the Mössbauer spectrum of eutectoid pearlite consists of three sextets, i.e., a sextet of $\alpha-\mathrm{Fe}$, a sextet of a small quantity of impurities and a sextet of the cementite phase. Since the existence of different impurity configuration determines the relative amplitudes of these sextets, ${ }^{[54]}$ the area fractions of the subspectra can be evaluated by calculating the fractions of Fe atoms that are affected by the concerned impurities. ${ }^{[33]} \mathrm{A}$ comparison of changes in the area fractions of the Mössbauer spectrum of cementite at each condition in Figure 6 shows that the cementite undergoes partial decomposition. One interesting feature to note is that the fraction of cementite decreases rapidly and then fluctuates at a certain value. However, Figure 6 shows that the rapid decrease in cementite fraction occurs in the first 150 cycles. Heavy plastic deformation of cementite induces cementite dissolution, which is very pronounced in heavy cold drawing. ${ }^{[24,32]}$
Hence, cementite decomposition is ascribed mainly to heavy plastic deformation at the beginning of cyclic loading.

\section{DISCUSSION}

Now, two interesting questions naturally arise: how do dislocation evolution and carbon atoms from the decomposed cementite affect ratchetting in pearlitic steel? And what is the mechanism for cementite decomposition. These two questions will be discussed in detail as follows.

Dislocation-based plasticity is a dominating mechanism in ratchetting strain accumulation, whereas the effect of the carbon-pinning mechanism is not negligible. Steel wire material directly undergoes heavy plastic deformation after yielding, and is accompanied by cementite decomposition as well as a decrease in ILS. Many researchers have found that lattice dislocations could nucleate from the interface. ${ }^{[55-57]}$ Guziewski 

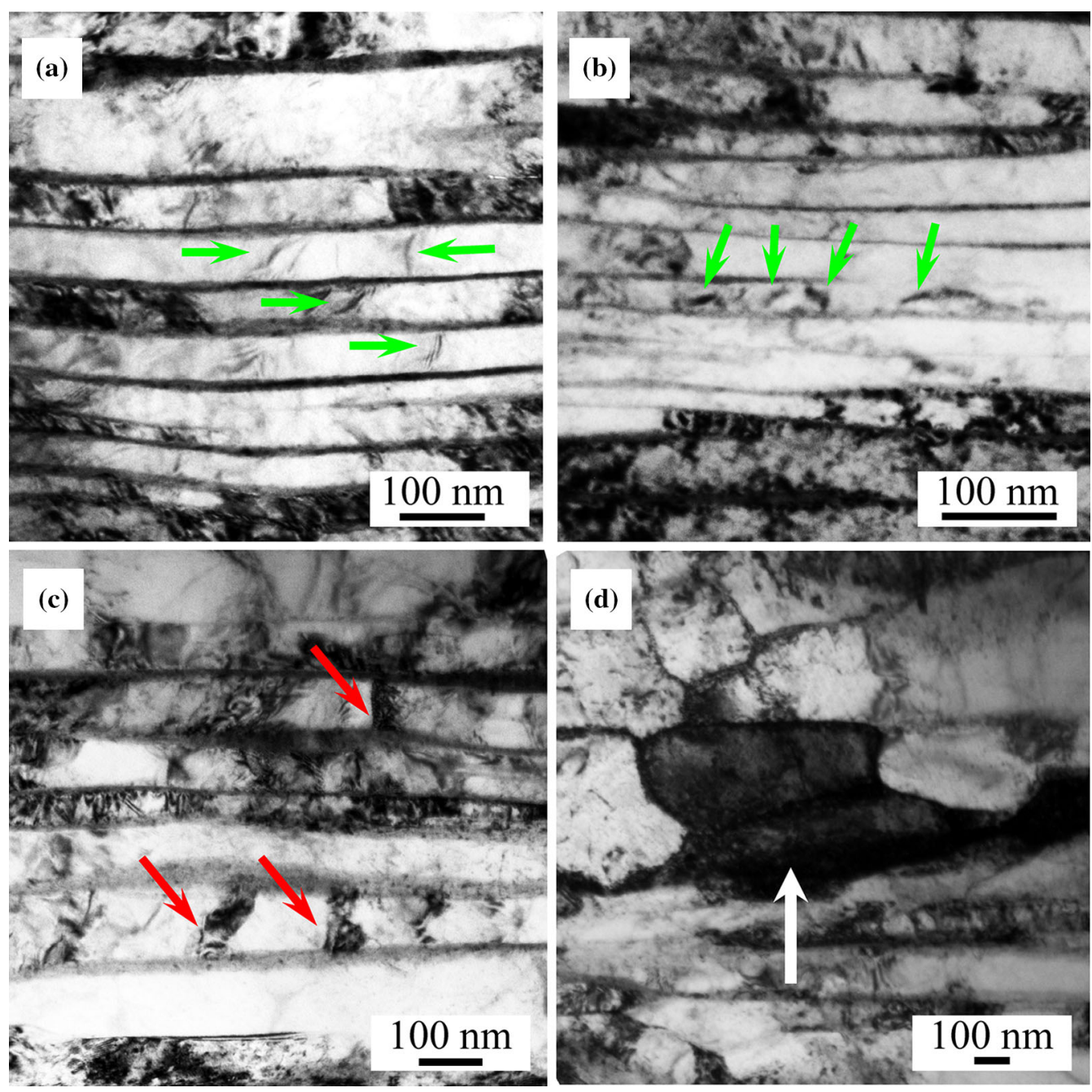

Fig. 4-TEM images of specimens at different cyclic numbers. (a) Dislocation lines at $N=0$. Reproduced with permission from Ref. [50]. (b) Dislocation lines and tangles at $N=500$. (c) Dislocation cells at $N=3000$. (d) Sub-grain at $N=5000$. Green and red arrows point to dislocation lines and dislocation cell boundaries in the ferrite layers, respectively. The white arrow points to a sub-grain.

et $a l .{ }^{[58]}$ predicted recently that dislocation loops nucleate from the ferrite-cementite interface because of the mismatch in lattice upon yielding. Dislocation tangles (shown in Figure 4(b)) form with a relatively high dislocation density, which occurs because newly nucleated dislocations from the ferrite-cementite interface intersect with previously existing dislocations and the originally parallel dislocation relationship (shown in Figure 4(a)) is broken. With an increase in the number of cycles, dislocation cells are observed. With a further increase in the cyclic numbers, sub-grains form by dislocation rearrangement in dislocation cells since dislocation cross-slip occurs easily in BCC crystals.

A competitive relationship exists between the dislocation multiplication and carbon-pinning mechanisms. In stage I of the ratchetting deformation, the quick multiplication of dislocation causes carbon-pinning mechanism effect to be ignored, which leads to the rapid increase in ratchetting strain. In stage II, subgrains are formed by dislocation rearrangement in the dislocation cells because the cross-slip of dislocations occurs easily in BCC crystals, which causes an approximately constant ratchetting strain rate due to no obvious increase in dislocation density. The carbon-pinning mechanism should be considered because no apparent dislocation multiplication takes place. Carbon atoms that are dissolved from cementite enter adjacent ferrite layers, pin dislocations and limit their movements, which results in a lower ratchetting strain rate that is nearly close to zero.

Theoretically, the simplest process for cementite dissolution can be represented schematically by the $\mathrm{Fe}_{3} \mathrm{C} \rightarrow 3 \mathrm{Fe}+\mathrm{C}_{\text {sol-sol-type reaction. }}{ }^{[26]}$ However, some researchers have reported some different values that deviate from the strict $\mathrm{Fe}_{3} \mathrm{C}$ composition, ${ }^{[22,59-62]}$ which suggests that cementite should be considered as an interstitial phase, $\mathrm{Fe}_{3} \mathrm{C}_{1-\mathrm{x}}$. Therefore, the process for cementite dissolution can be expressed more reasonably as: $\mathrm{Fe}_{3} \mathrm{C} \rightarrow \mathrm{Fe}_{3} \mathrm{C}_{1-\mathrm{x}}+\mathrm{C}_{\text {sol-sol. }}$. Due to the special lamellar structure of cold-drawn pearlitic steel wires, the effect of the surface-to-volume ratio of cementite should be considered. The Gibbs-Thomson equation assumes that the interfacial tension between ferrite and cementite can be estimated by: $S_{\mathrm{fer} / \mathrm{cem}} R=P_{\text {cem }}-P_{\text {fer }}$. 


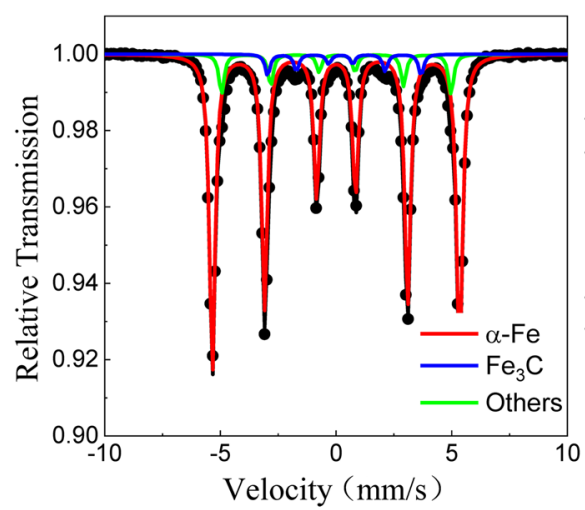

(a)

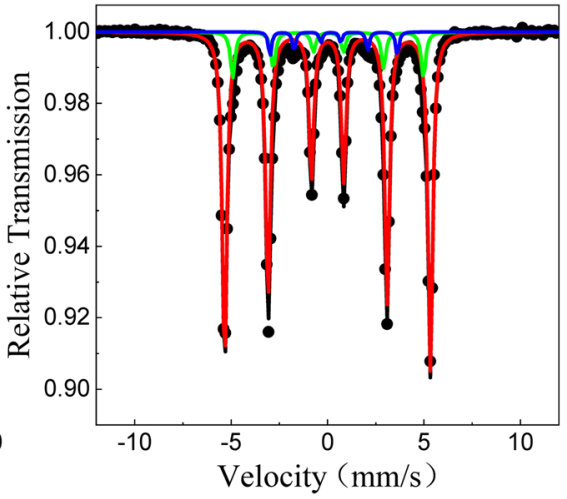

(b)

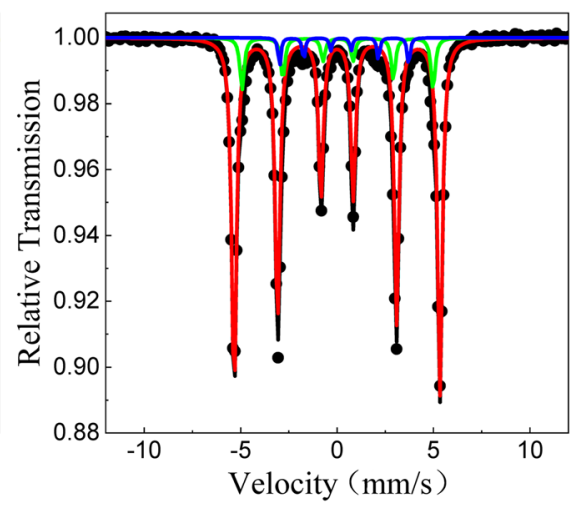

(c)

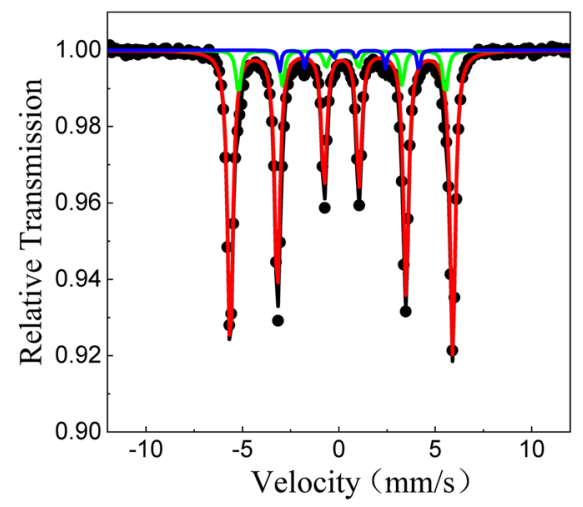

(d)

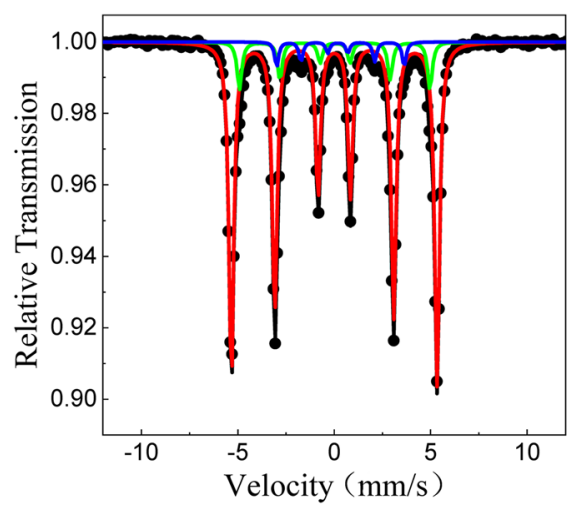

(e)

Fig. 5-Mössbauer spectra of steel samples at different number of cycles. (a) $N=0,(b) N=150,(c) N=1500,(d) N=3000,(e) N=5000$.

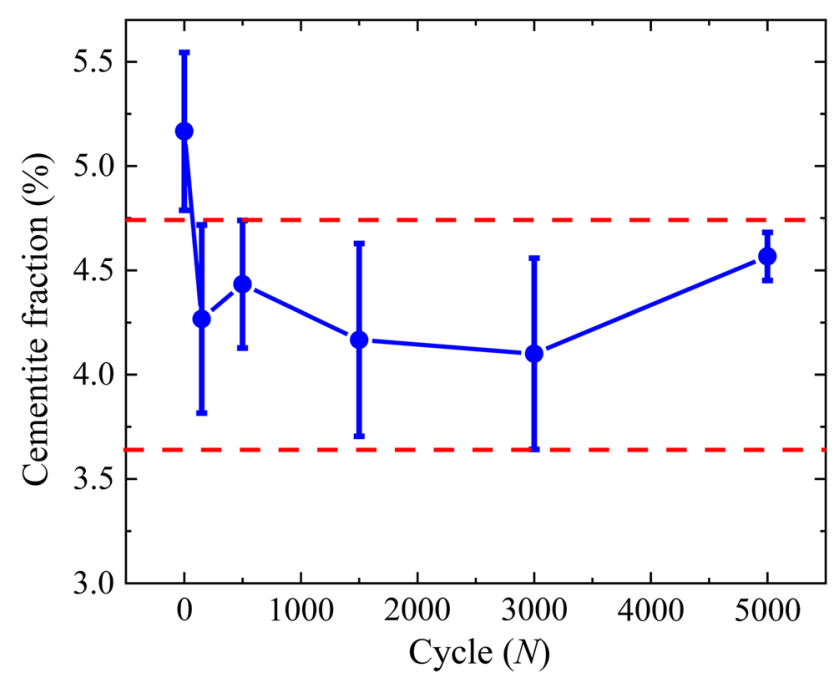

Fig. 6-Variation of cementite fraction as a function of cycle numbers.

Here $R$ denotes the curvature of the interface, and $P_{\text {cem }}$ and $P_{\text {fer }}$ correspond to the pressures in cementite and ferrite, respectively. Thus, the heavy plastic strain induces a larger interfacial tension since the stiffness of the cementite is higher than that of the ferrite and two phases exist in the same strain state $\left(\right.$ Voigt limit $\left.^{[63]}\right)$. ILS is inversely proportional to the axial strain. The increased surface-to-volume ratio because of the decreasing thickness of the ILS destabilizes the cementite and leads to its dissolution. The dissolution reduces the interfacial tension because the introduction of interstitial carbon atoms does not alter the stiffness of the ferrite significantly, but softens that of cementite. ${ }^{[64]}$ Therefore, nearly no cementite decomposition is attributed to the fact that the lamellar spacing does not change.

Some researchers attribute the micro-mechanism of cementite decomposition to the role of dislocations ${ }^{[28,53,65]}$ since the binding of carbon to dislocations is higher than that of carbon in cementite,${ }^{[1]}$ although the pipe diffusion mechanism or drag mechanism is unclear. An atomistic simulation supports the dislocation drag mechanism by which mobile dislocations can collect and drag carbon within their cores from the cementite into adjacent ferrite. ${ }^{[66]}$ The dislocation drag mechanism may prevail in our opinion. Dislocations that are pinned at the ferrite-cementite interface enhance the instability of cementite lamellae by making it polycrystalline or amorphous. ${ }^{[65]}$ The carbon atoms in cementite layers can be collected and dragged out by the dislocation. Therefore, the cementite decomposes rapidly at the beginning of the cyclic loading owing to the rapid nucleation and migration of dislocations from the ferrite-cementite interface. However, carbon atoms from decomposed cementite pin up dislocations and 
hinder the movement of dislocations, which inhibits further cementite decomposition.

\section{CONCLUSIONS}

In summary, cementite decomposition occurs at the beginning of the cyclic loading in cold-drawn pearlitic steel wires. The initial rapid increase in ratchetting strain is believed to stem from dislocation multiplication due to heavy plastic deformation. At a later stage, a nearly constant ratchetting strain rate is established with combined roles of dislocation multiplication and blocked dislocation motion by decomposed carbon atoms in ferrite. Higher dislocation density patterns are formed as dislocation cells and sub-grains. Cementite decomposition may depend on the unfavorable surface-to-volume ratio of cementite and the dislocation drag mechanism.

\section{ACKNOWLEDGMENTS}

This work is supported financially by the National Key Research and Development Program of China (No. 2017YFB0702003), the NSFC (No. 11472287, No. 11790292, and No. 11572324), the Strategic Priority Research Program of the Chinese Academy of Sciences (Grant Nos. XDB22040302 and XDB22040303), and the Key Research Program of Frontier Sciences of the Chinese Academy of Sciences (Grant No. QYZDJSSW-JSC011).

\section{REFERENCES}

1. C. Borchers and R. Kirchheim: Prog. Mater. Sci., 2016, vol. 82, pp. $405-44$.

2. J. Embury and R. Fisher: Acta Metall., 1966, vol. 14, pp. 147-59.

3. K. Maurer and D. Warrington: Philos. Mag., 1967, vol. 15, pp. 321-27.

4. G. Langford: Metall. Mater. Trans. B., 1970, vol. 1, pp. 465-77.

5. J.G. Sevillano: Mater. Sci. Eng., 1975, vol. 21, pp. 221-25.

6. A. Inoue, T. Ogura, and T. Masumoto: Metall. Trans. A., 1977, vol. 8, pp. 1689-95.

7. V. Gridnev, V. Gavrilyuk, I.Y. Dekhtyar, Y.Y. Meshkov, P. Nizin, and V. Prokopenko: Phys. Stat. Sol. (a)., 1972, vol. 14, pp. $689-94$

8. J. Languillaume, G. Kapelski, and B. Baudelet: Acta Mater., 1997, vol. 45 , pp. 1201-12.

9. H.G. Read, W.T.R. Jr, K. Hono, and T. Tarui: Scripta Mater., 1997, vol. 37, pp. 1221-30.

10. X. Sauvage, J. Copreaux, F. Danoix, and D. Blavette: Philos. Mag. A., 2000, vol. 80, pp. 781-96.

11. V.G. Gavriljuk: Mater. Sci. Eng. A., 2003, vol. 345, pp. 81-89.

12. T. Tarui, N. Maruyama, J. Takahashi, S. Nishida, and H. Tashiro: Nippon Steel Tech. Rep., 2005, vol. 91, pp. 56-61.

13. Z.-A. Lv, P. Jiang, Z.-H. Wang, W.-H. Zhang, S.-H. Sun, and W.-T. Fu: Mater. Lett., 2008, vol. 62, pp. 2825-27.

14. C. Borchers, R. Kirchheim, T. Al-Kassab, and S. Goto: Mater. Sci. Eng. A., 2009, vol. 502, pp. 131-38.

15. J. Takahashi, T. Tarui, and K. Kawakami: Ultramicroscopy., 2009, vol. 109, pp. 193-99.

16. J. Park, S.-D. Kim, S.-P. Hong, S.-I. Baik, D.-S. Ko, C.Y. Lee, D.-L. Lee, and Y.-W. Kim: Mater. Sci. Eng. A., 2011, vol. 528, pp. 4947-52.
17. X. Zhang, A. Godfrey, X. Huang, N. Hansen, and Q. Liu: Acta Mater., 2011, vol. 59, pp. 3422-30.

18. S. Goto, R. Kirchheim, T. Al-Kassab, and C. Borchers: Trans. Nonferrous Met. Soc. China., 2007, vol. 17, pp. 1129-38.

19. C. Borchers, T. Al-Kassab, S. Goto, and R. Kirchheim: Mater. Sci. Eng. A., 2009, vol. 502, pp. 131-38.

20. F. Fang, Y. Zhao, P. Liu, L. Zhou, X.-J. Hu, X. Zhou, and Z.-H. Xie: Mater. Sci. Eng. A., 2014, vol. 608, pp. 11-15.

21. C. Jiang, S.A. Maloy, and S.G. Srinivasan: Scripta Mater., 2008, vol. 58 , pp. $739-42$.

22. V.I. Voronin, I.F. Berger, Y.N. Gornostyrev, V.N. Urtsev, A.R. Kuznetsov, and A.V. Shmakov: JETP Lett., 2010, vol. 91, pp. 143-46.

23. M.H. Hong, W.T. Reynolds, T. Tarui, and K. Hono: Metall. Mater. Trans. A., 1999, vol. 30, pp. 717-27.

24. K. Hono, M. Ohnuma, M. Murayama, S. Nishida, A. Yoshie, and T. Takahashi: Scripta Mater., 2001, vol. 44, pp. 977-83.

25. N. Maruyama, T. Tarui, and H. Tashiro: Scripta Mater., 2002, vol. 46, pp. 599-603.

26. F. Danoix, D. Julien, X. Sauvage, and J. Copreaux: Mater. Sci. Eng. A., 1998, vol. 250, pp. 8-13.

27. M. Hong, K. Hono, W. Reynolds, and T. Tarui: Metall. Mater. Trans. A., 1999, vol. 30, pp. 717-27.

28. X. Sauvage, W. Lefebvre, C. Genevois, S. Ohsaki, and K. Hono: Scripta Mater., 2009, vol. 60, pp. 1056-61.

29. Y.J. Li, P. Choi, C. Borchers, Y.Z. Chen, S. Goto, D. Raabe, and R. Kirchheim: Ultramicroscopy., 2011, vol. 111, pp. 628-32.

30. V. Gavrilyuk, D. Gertsriken, Y.A. Polushkin, and A. Fal'chenko: Fiz. Mekh. Mater., 1981, vol. 51, pp. 147-52.

31. V. Gridnev and V. Gavrilyuk: Phys. Met. (USSR)., 1982, vol. 4, pp. 531-51.

32. W.J. Nam, C.M. Bae, S.J. Oh, and S.J. Kwon: Scripta Mater., 2000, vol. 42, pp. 457-63.

33. N. Min, W. Li, H. Li, and X. Jin: J. Mater. Sci. Technol., 2010, vol. 26, pp. 776-82.

34. J. Chakraborty, M. Ghosh, R. Ranjan, G. Das, D. Das, and S. Chandra: Philos. Mag., 2013, vol. 93, pp. 4598-616.

35. V. Gavriljuk: Mater. Sci. Eng. A., 2003, vol. 345, pp. 81-89.

36. N. Ohno: J. Soc. Mater. Sci. Jpn., 1997, vol. 46, pp. 1-9.

37. S. Bari and T. Hassan: Int. J. Plast., 2002, vol. 18, pp. 873-94.

38. G. Kang: Int. J. Fatigue., 2008, vol. 30, pp. 1448-72.

39. G. Kang, Y. Dong, H. Wang, Y. Liu, and X. Cheng: Mater. Sci. Eng. A., 2010, vol. 527, pp. 5952-61.

40. J.L. Chaboche: Int. J. Plast., 2008, vol. 24, pp. 1642-93.

41. P.J. Armstrong and C. Frederick: A Mathematical Representation of the Multiaxial Bauschinger Effect, Nuclear Laboratories, Berkeley, 1966.

42. K. Saï: Int. J. Plast., 2011, vol. 27, pp. 250-81.

43. L. Bocher, P. Delobelle, P. Robinet, and X. Feaugas: Int. J. Plast., 2001, vol. 17, pp. 1491-530.

44. X. Feaugas and C. Gaudin: Int. J. Plast., 2004, vol. 20, pp. 643-62.

45. C. Gaudin and X. Feaugas: Acta Mater., 2004, vol. 52, pp. $3097-110$

46. J. Zhang and Y. Jiang: Int. J. Plast., 2005, vol. 21, pp. 2191-211. 47. L. Taleb and A. Hauet: Int. J. Plast., 2009, vol. 25, pp. 1359-85.

48. A. Ghosh and N.P. Gurao: Mater. Des., 2016, vol. 109, pp. 186-96.

49. G. Kang, Y. Dong, Y. Liu, H. Wang, and X. Cheng: Mater. Sci. Eng. A., 2011, vol. 528, pp. 5610-20.

50. L. Xiang, L.W. Liang, Y.J. Wang, Y. Chen, H.Y. Wang, and L.H. Dai: Mater. Sci. Eng. A., 2019, vol. 757, pp. 1-13.

51. N. Ridley: Metall. Mater. Trans. A., 1984, vol. 15, pp. 1019-36.

52. X. Hu, P. Van Houtte, M. Liebeherr, A. Walentek, M. Seefeldt, and H. Vandekinderen: Acta Mater., 2006, vol. 54, pp. 1029-40.

53. Y.J. Li, P. Choi, C. Borchers, S. Westerkamp, S. Goto, D. Raabe, and R. Kirchheim: Acta Mater., 2011, vol. 59, pp. 3965-77.

54. V.G. Gavrilyuk, V.G. Prokopenko, and O.N. Razumov: Phys. Stat. Sol. (a)., 1979, vol. 53, pp. 147-54.

55. J. Wang and A. Misra: Curr. Opin. Solid State Mater. Sci., 2011, vol. 15 , pp. $20-28$.

56. M.J. Demkowicz and L. Thilly: Acta Mater., 2011, vol. 59, pp. $7744-56$

57. I.J. Beyerlein, M.J. Demkowicz, A. Misra, and B.P. Uberuaga: Prog. Mater. Sci., 2015, vol. 74, pp. 125-210.

58. M. Guziewski, S.P. Coleman, and C.R. Weinberger: Acta Mater., 2018, vol. 144 , pp. $656-65$ 
59. F.X. Kayser and Y. Sumitomo: J. Phase Equilib., 1997, vol. 18, pp. $458-64$.

60. N. Medvedeva, A. Ivanovskii, and L. Kar'kina: Phys. Met. Metall., 2003, vol. 96, pp. 452-56.

61. L. Battezzati, M. Baricco, and S. Curiotto: Acta Mater., 2005, vol. 53, pp. $1849-56$

62. N.I. Medvedeva, L.E. Kar'kina, and A.L. Ivanovskii: Phys. Met. Metall., 2006, vol. 101, p. 440.

63. B. Harris: Engineering Composite Materials, Institute of metals, London, 1986.
64. G.A. Nematollahi, J. von Pezold, J. Neugebauer, and D. Raabe: Acta Mater., 2013, vol. 61, pp. 1773-84.

65. F. Fang, Y. Zhao, P. Liu, L. Zhou, X.-J. Hu, X. Zhou, and Z.-H. Xie: Mater. Sci. Eng. A., 2014, vol. 608, pp. 11-15.

66. G.A. Nematollahi, B. Grabowski, D. Raabe, and J. Neugebauer: Acta Mater., 2016, vol. 111, pp. 321-34.

Publisher's Note Springer Nature remains neutral with regard to jurisdictional claims in published maps and institutional affiliations. 